\title{
Editorial
}

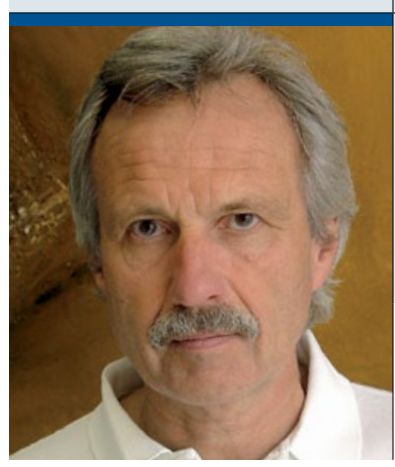

"Wem ist damit geholfen, wenn Patienten,

denen ein Behandlungsfehler widerfahren ist, in das Klischee

der Sozialneiddebatte verfallen?"

Dr. med. Michael Pieper (Chefredakteur),

Orthopäde am Endocenter Damme

\section{Hetze und Häme}

W ulff ist medientechnisch „abgegrast“, nun sind mal wieder die Ärzte dran! Gemäß ihrem Motto „Lass Dir Deine Meinung ver-Bild-en“ brachte es die Zeitung mit den Großlettern für sehgeschädigte Halbgescheite auf den marktschreierischen Punkt: „1.712 Tote durch Ärztepfusch“. Und das "Aktionsbündnis Patientensicherheit“ setzte gleich noch eins drauf: Dies sei nur die „Spitze des Eisbergs“, man gehe von jährlich 17.000 Toten durch ärztliche Behandlungsfehler aus.

Was veranlasst eigentlich die Presse und die diversen Klübchen selbsternannter Patientenfürsprecher, die meist aus einer erstaunlich großen Anzahl an Vorsitzenden und Geschäftsführern bestehen, ohne solide Recherche derlei plakative Slogans zu verbreiten? Was soll das bringen? Wem nutzt das? „Es geht nicht darum, Ärzte und Krankenhäuser an den Pranger zu stellen“ betont die Sprecherin des Vereins für „Prävention und Patientenrechte“, man wolle nur eine „Kultur der Fehlervermeidung und des Risikomanagements in der Breite etablieren."Wenn das wirklich Programm ist, dann sollte man sich erst recht um eine solide und präzise Aufarbeitung der herangezogenen Statistiken bemühen und sich nicht in markigen Stammtischsprüchen ergehen.

\section{Sinnlose Diffamierung}

Wem ist damit geholfen, wenn - wie kürzlich in einer Fernsehsendung - Patienten, denen ein Behandlungsfehler widerfahren ist, in das Klischee der Sozialneiddebatte verfallen und mutmaßen, dass Behandlungsfehler grundsätzlich vertuscht würden, weil Ärzte und Gutachter auf dem Golfplatz regelmäßig Schweigedeals aushandeln.

Soll etwas bewirkt werden, dann ist ein gewisses $\mathrm{Ma}$ an Differenziertheit in der subtentoriellen Höhle hierfür Voraussetzung. Solange Patienten mit Unverständnis, sogar feindseliger Aggression reagieren, wenn die Ursache einer Befindlichkeitsstörung nicht zu eruieren ist, wird es zu keinem Konsens kommen.

\section{Unproduktive Strafexpedition}

Solange sich Ärzte, denen ein Fehler unterlaufen ist, mit unterbeschäftigten Rechtsanwälten mit dem inflationär zunehmenden Spezialgebiet Medizinrecht konfrontiert sehen, deren Primat es ist, nicht den begangenen Fehler, sondern eine vorsätzlich und fahrlässig begangene Untat mit strafrechtlichen Konsequenzen nachzuweisen, um die Entschädigungsumme in die Höhe zu treiben, solange wird es eine Kultur der lehrenden Fehlerbearbeitung nicht geben. Das gilt es auch zu bedenken, wenn einer aus der Gruppe der volksgewählten Selbstdarsteller über ein neues Patientenrechtegesetz und eine Aufstockung der Haftpflichtsummen für ärztliche Tätigkeiten schwadroniert.

\section{Harte Indikationskriterien}

Würde man die einst strengen Voraussetzungen für elektive operative Eingriffe wie ein vernünftiges Körpergewicht wiederbeleben, statt XXL-OP-Tische anzuschaffen, oder bei den Patienten eine Disziplin und geistige Qualifikation voraussetzen, die der Einsicht in die Behandlung und Nachbehandlung nicht im Wege stehen, würde die erbrachte ärztliche Leistung wieder einen geschätzten Stellenwert erfahren. Und wir müssten keine Sendungen und Moderatoren wie Anne Will mehr ertragen, die den Tod von Säuglingen nutzt, um eine subversive Desavouierung des Gesundheitswesens in die Frage münden zu lassen, ob man sich einem Risikoort wie dem Krankenhaus noch anvertrauen dürfe. Nein, Frau Will! Sie lassen die Einsicht reifen, sich nicht länger mit Fallobst zu beschäftigen.

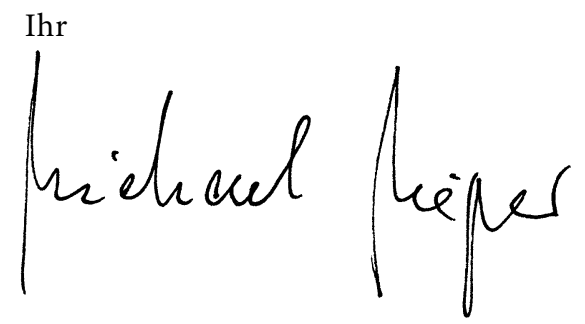

